\title{
Dose of Continuous Renal Replacement Therapy in Critically III Patients: A Bona Fide Quality Indicator
}

\author{
Enzo Vásquez Jiménez ${ }^{a}$ Samaya J. Anumudu ${ }^{b}$ Javier A. Neyra ${ }^{c}$ \\ aDepartment of Nephrology, National Institute of Cardiology Mexico, Mexico City, Mexico; \\ bivision of Nephrology, Department of Internal Medicine, Baylor College of Medicine, Houston, TX, USA; \\ 'Division of Nephrology, Department of Internal Medicine, Bone and Mineral Metabolism, University of Kentucky, \\ Lexington, KY, USA
}

\section{Keywords}

Acute kidney injury · Quality metric · Quality indicator ·

Continuous renal replacement therapy · Dose

\begin{abstract}
Acute kidney injury (AKI) is common in critically ill patients, and renal replacement therapy (RRT) constitutes an important aspect of acute management during critical illness. Continuous RRT (CRRT) is frequently utilized in intensive care unit settings, particularly in patients with severe AKI, fluid overload, and hemodynamic instability. The main goal of CRRT is to timely optimize solute control, acid-base, and volume status. Total effluent dose of CRRT is a deliverable that depends on multiple factors and therefore should be systematically monitored (prescribed vs. delivered) and iteratively adjusted in a sustainable mode. In this manuscript, we review current evidence of CRRT dosing and provide recommendations for its implementation as a quality indicator of CRRT delivery.

(c) 2021 S. Karger AG, Basel
\end{abstract}

\section{Introduction}

Acute kidney injury (AKI) is a frequent complication encountered in critically ill patients admitted to intensive care units (ICUs) and is associated with increased morbidity and mortality. About $5-15 \%$ of the critically ill patients with AKI in the ICU require renal replacement therapy (RRT) [1-3], which carries mortality rates up to $70 \%$ [4-7]. In the multinational prospective AKI-EPI study, $57 \%$ of the ICU patients had AKI and $13.5 \%$ required RRT, most of them (75\%) in the form of continuous RRT (CRRT) [8].

The dose of CRRT remains a highly variable CRRT deliverable as it encompasses a broad concept of clearance with multiple challenges for its measurement and application [9]. Like other extracorporeal support treatment, the provision of CRRT requires a timely prescription and a specific dose to achieve its main goals of solute and volume control. The dose of CRRT relates to clearance measured as the removal rate of urea, which is a small solute with a sieving coefficient of approximately 1 $[10,11]$. There are several patient- and machine-specific factors that influence CRRT dosing in critically ill patients with AKI in the ICU. Therefore, total effluent dose

$\begin{aligned} & \text { karger@karger.com } \\ & \text { www.karger.com/nef }\end{aligned}$
Karger ${ }^{\prime /}$

Javier A. Neyra

University of Kentucky Medical Center

800 Rose St., MN668

Lexington, KY 40536 (USA)

javier.neyra@uky.edu 


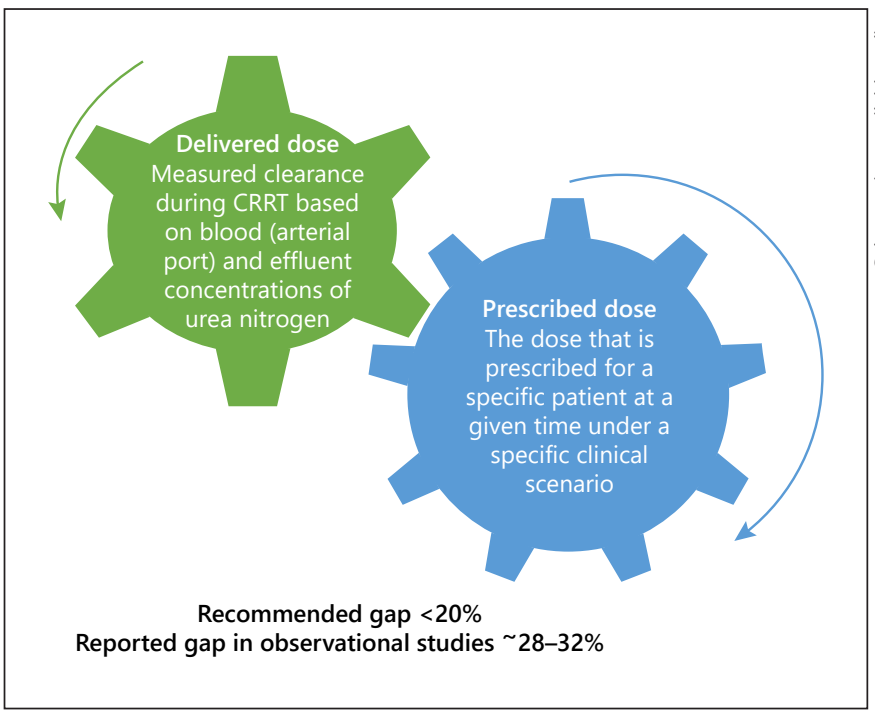

Fig. 1. Conceptual difference between prescribed and delivered CRRT dose. CRRT, continuous renal replacement therapy.

of CRRT should be evaluated frequently to accommodate timely changes according to specific goals of therapy [12].

The optimal delivery of CRRT requires iterative assessment, coordination, and communication among multiple stakeholders in the ICU. The systematic evaluation of CRRT quality indicators/metrics (e.g., CRRT dose) is a critical first step in the development of quality assurance systems that support CRRT delivery. The selection of quality indicators and the goals of quality assurance systems should be customized to specific logistics and needs of each institution [13]. In this manuscript, we review current evidence of CRRT dosing and provide recommendations for its implementation as a quality indicator of CRRT delivery.

\section{CRRT Dose as a Novel Quality Indicator: Why Is It Important?}

The optimal delivery of CRRT should be a dynamic, precise, and sustainable process that is informed by evidence-based medicine and accommodates precision medicine in the acutely ill [10]. The concept of dynamic CRRT delivery consists of adapting the treatment according to time-varying changes in the clinical status of the critically ill patient, which implies that audits, feedback, and quality indicators are incorporated in the decisionmaking process $[14,15]$.

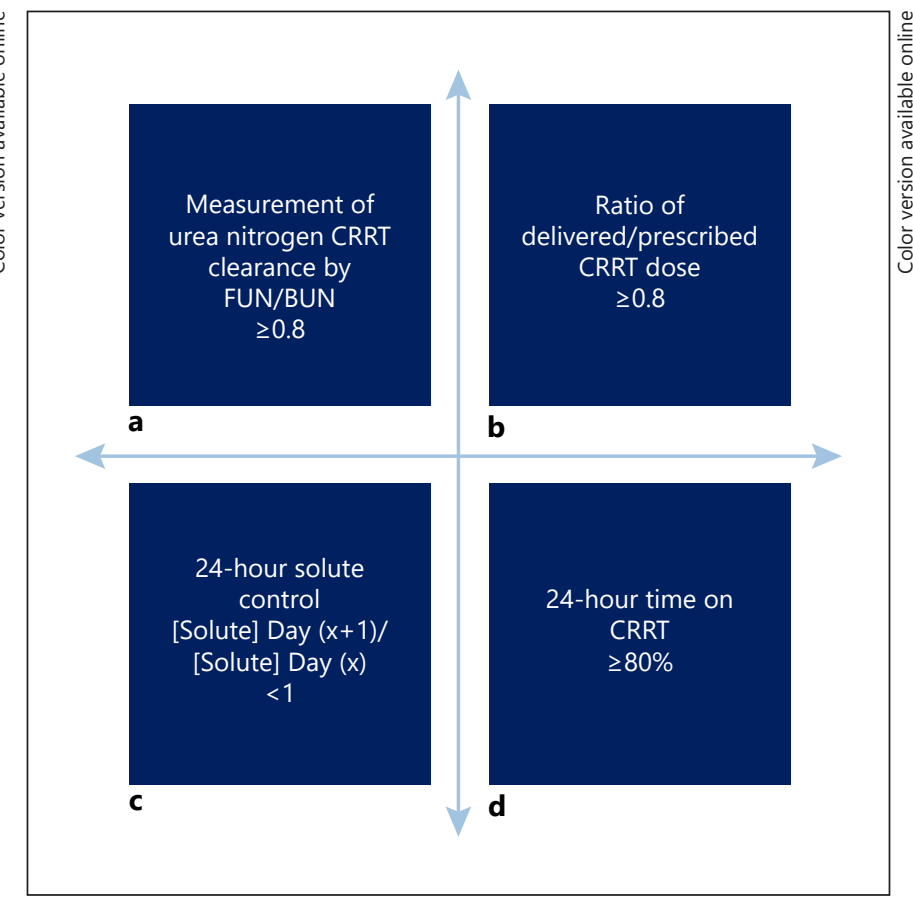

Fig. 2. Quality indicators related to delivered CRRT dose. a Clearance of urea nitrogen delivered with CRRT can be measured by the ratio of effluent urea nitrogen to BUN (arterial port) and should be maintained above 0.8 on average. $\mathbf{b}$ The ratio of delivered to prescribed CRRT dose should be maintained above 0.8 on average. c Change in blood concentrations of small solutes (e.g., urea nitrogen) evaluated in 24-h cycles can also indicate CRRT adequacy for solute removal. d Time on CRRT is a critical aspect to effectively deliver the prescribed CRRT dose. CRRT, continuous renal replacement therapy.

There is wide variation in the delivery of CRRT across centers, and there are limited data on validation of CRRT quality indicators/metrics and their impact on clinical and patient-centered outcomes [16]. Therefore, development of quality assurance programs represents one way to continuously measure, monitor, communicate, and improve specific aspects of CRRT delivery [14]. In this context, delivered CRRT dose (Fig. 1) represents an ideal quality indicator of CRRT adequacy which can be monitored by the ratio of delivered to prescribed CRRT dose and should be maintained above 0.8 on average (Fig. 2) $[11,16]$.

A recent study identified 18 potential quality indicators to evaluate CRRT delivery by using the Donabedian domains of structure, processes of care, and patient outcomes. The most commonly used quality metrics focused on filter lifespan, small solute clearance, bleeding, delivered dose, and treatment interruptions, although there 
Table 1. Calculation of total effluent fluid rate according to CRRT modality

Example: weight $70 \mathrm{~kg}, \mathrm{HCT}=30 \%$, blood flow rate $=150 \mathrm{~mL} / \mathrm{min}$, pre-filter replacement $=1,000 \mathrm{~mL} / \mathrm{h}$, post-filter replacement $=$ $400 \mathrm{~mL} / \mathrm{h}$, dialysate rate $=800 \mathrm{~mL} / \mathrm{h}$, fluid removal rate $=200 \mathrm{~mL} / \mathrm{h}$

CVVH: total UF rate, $m L / h+$ fluid removal rate, $m L / h$

Example: CVVH: 1,400 mL/h $+200 \mathrm{~mL} / \mathrm{h}$

Effluent flow rate $=22.9 \mathrm{~mL} / \mathrm{kg} / \mathrm{h}(19.8 \mathrm{~mL} / \mathrm{kg} / \mathrm{h}$ adjusted by dilution factor $)$

CVVHD: dialysate rate, $m L / h+$ fluid removal rate, $m L / h$

Example: CVVHD: $800 \mathrm{~mL} / \mathrm{h}+200 \mathrm{~mL} / \mathrm{h}$

Effluent flow rate $=14.3 \mathrm{~mL} / \mathrm{kg} / \mathrm{h}$

CVVHDF: total UF rate, $m L / h+$ dialysate rate, $m L / h+$ fluid removal rate, $m L / h$

Example: CVVHDF: $1,400 \mathrm{~mL} / \mathrm{h}+800 \mathrm{~mL} / \mathrm{h}+200 \mathrm{~mL} / \mathrm{h}$

Effluent flow rate $=34.3 \mathrm{~mL} / \mathrm{kg} / \mathrm{h}(29.6 \mathrm{~mL} / \mathrm{kg} / \mathrm{h}$ adjusted by dilution factor $)$

Dilution factor for predilution: plasma flow rate, $\mathrm{mL} / \mathrm{h} /$ [plasma flow rate, $\mathrm{mL} / \mathrm{h}+$ pre-filter replacement fluid rate, $\mathrm{mL} / \mathrm{h}$ ]

Total UF rate, $\mathrm{mL} / \mathrm{h}=$ pre-filter replacement fluid rate, $\mathrm{mL} / \mathrm{h}+$ post-filter replacement fluid rate, $\mathrm{mL} / \mathrm{h}$

Plasma flow rate, $\mathrm{mL} / \mathrm{h}=$ blood flow rate, $\mathrm{mL} / \mathrm{min} \times 60, \mathrm{~min} / \mathrm{h} \times(1-\mathrm{HCT})$; where HCT is the current hematocrit of the patient

CRRT, continuous renal replacement therapy; UF, ultrafiltration; CVVH, continuous venovenous hemofiltration; CVVHD, continuous venovenous hemodialysis; CVVHDF, continuous venovenous hemodiafiltration; HCT, current hematocrit.

was significant heterogeneity in the definitions [17]. Later, using a Delphi process, a list of 13 quality indicators (including delivered CRRT dose) was proposed for inclusion into routine clinical practice and for development of a quality assurance panel to monitor CRRT delivery [18].

Frequent training of the nursing and clinician staff is a strategy that has been shown to decrease the occurrence of unplanned CRRT interruptions to optimize delivered CRRT dose [19]. Mottes et al. [20] reported the implementation of a CRRT quality dashboard based on categories such as filter life, prescribed versus delivered dose, and fluid balance for the evaluation of adherence to evidence-based practices and tracking of quality indicators of CRRT. The authors observed that the proportion of patients achieving at least $90 \%$ of the prescribed dose increased from 87 to $100 \%$ by reinforcement of education strategies and continuous monitoring through the dashboard [20].

\section{Practical Considerations to Determine CRRT Dose}

The total effluent fluid rate is a surrogate of solute clearance provided by CRRT and is used to determine the dose of CRRT in diffusive, convective, and hybrid modalities. The total effluent rate is typically reported in milliliters per hour and adjusted by the patient's weight in kilograms $(\mathrm{mL} / \mathrm{kg} / \mathrm{h})$. The determination of the total ef- fluent rate varies according to CRRT modality. In continuous venovenous hemofiltration $(\mathrm{CVVH}$, convective clearance), it is equivalent to the total ultrafiltration rate (the sum of pre-filter replacement fluid rate, post-filter replacement fluid rate, and the patient's net fluid removal rate). In continuous venovenous hemodialysis ( $\mathrm{CV}$ $\mathrm{VHD}$, diffusive clearance), it is the sum of dialysate fluid rate plus the patient's net fluid removal rate, and in continuous venovenous hemodiafiltration (CVVHDF, convective and diffusive clearance), it is the sum of dialysate fluid rate and total ultrafiltration rate $[1,21]$ (Table 1).

When using pre-filter replacement fluid in CVVH or CVVHDF modes, the blood entering the circuit is diluted and therefore clearance is decreased. In this setting, the total effluent fluid rate should be multiplied (adjusted) by a dilution factor that is calculated as follows:

Dilution Factor $=$ Plasma Flow Rate* $(m L / h) /[$ Plasma Flow Rate* $^{*}(\mathrm{~mL} / \mathrm{h})+$ Pre-Filter Replacement Fluid Rate $\left.(\mathrm{mL} / \mathrm{h})\right]$ $*$ Plasma Flow Rate $(\mathrm{mL} / \mathrm{h})=$ Blood Flow Rate $(\mathrm{mL} / \mathrm{min}) \times 60$ $(\mathrm{min} / \mathrm{h}) \times(1-\mathrm{HCT})$; where HCT is the current hematocrit of the patient and BFR is blood flow rate.

When using diffusive clearance (CVVHD), dialysate flow rate, concentration gradients, and filter surface area the latter to a lesser extend - are the main determinants of clearance [22]. When using convective clearance (CVVH or CVVHDF), one should recognize the concept of filtration fraction (FF), which is the proportion of plas- 
ma water entering the filter that is removed by ultrafiltration. FF is inversely proportional to the BFR. Therefore, a low $\mathrm{BFR}(<100 \mathrm{~mL} / \mathrm{min})$ could increase the risk of clotting due to stasis of blood (high FF). In contrast, a high BFR $(>250 \mathrm{~mL} / \mathrm{min})$ decreases FF but could affect circuit lifespan due to vascular access issues [23]. The use of prefilter replacement fluid helps to maintain a lower FF by diluting the blood entering the hemofilter but to the expense of a decrease in solute clearance. Troyanov et al. [24] showed an efficiency loss for urea clearance of about $35 \%$ when using $\mathrm{CVVH}$ with pre-filter replacement fluid. For this reason, it is recommended, in adult patients, to keep a BFR of $150-200 \mathrm{~mL} / \mathrm{min}$, particularly when using pre-filter replacement fluid rates of $>1,500 \mathrm{~mL} / \mathrm{h}[24,25]$.

There is no evidence-based consensus in relation to which patient's weight to use (admission weight, ideal weight, or current weight) when determining CRRT dose. However, it is recommended to use the current weight of the patient (at the time of determining CRRT dose) as it theoretically accommodates acute increases in the volume of distribution due to fluid overload. The KDIGO 2012 clinical practice guidelines suggest delivering an average effluent dose of $20-25 \mathrm{~mL} / \mathrm{kg} / \mathrm{h}$ for patients with AKI requiring CRRT [26]. However, the prescribed dose is not always delivered due to CRRT interruptions related to off-room procedures or circuit downtime due to clotting/clogging, replacing filters, bag/tubing changes, or dialysis catheter malfunction. Therefore, evaluation of the delivered dose and solute/volume control goals are recommended to adjust the CRRT prescription [27]. The CRRT dose could be tailored to accommodate specific patient needs at any given time and should account for possible hindrances that potentially preclude the goals of therapy.

One way to measure delivered CRRT dose is using the clearance equation of $\mathrm{U} / \mathrm{P} \times \mathrm{V}$, in which $\mathrm{U}$ represents the urea nitrogen concentration in the effluent fluid, $P$ represents the BUN concentration entering the circuit (arterial port), and $\mathrm{V}$ represents the total effluent fluid rate [28]. The ratio of effluent fluid urea nitrogen (FUN) by BUN should be approximately 1 at the beginning of treatment; however, FUN/BUN declines in parallel to a decrease in filter efficiency [29]. Multiple factors affect filter efficiency such as solute concentration polarization, solute fouling on the membrane surface (adsorption), and filter degradation/clogging [30, 31]. Therefore, FUN/ BUN is a valid measure of small solute clearance that can be helpful in certain clinical scenarios in which clearance needs to be properly quantified.

\section{Differentiating Prescribed versus Delivered CRRT Dose}

Venkataraman et al. [32] found that only $60 \%$ of the prescribed dose was effectively delivered in patients on CVVHD. In the DO-RE-MI study, a multicenter observational study of RRT practices in critically ill patients, only $22 \%$ of the patients prescribed a total effluent fluid rate of $\geq 35 \mathrm{~mL} / \mathrm{kg} / \mathrm{h}$ received the full dose [33]. In another study, Claure-Del Granado et al. [29] found that the delivered dose was only $73 \%$ of the prescribed dose when evaluated by measured urea clearance (FUN/BUN ratio) in patients treated with predilution CVVHDF. The decrease in urea clearance was attributed to circuit downtime and predilution (use of pre-filter replacement fluid). Similarly, Zhang et al. [34] demonstrated in 60 patients receiving CVVH that the delivered dose was 9.3\% lower than the prescribed dose, and this difference increased progressively over time as filter degraded. Furthermore, the authors showed that the difference between prescribed and delivered CRRT dose positively correlated with transmembrane pressures, indicating that filter clogging may have played a role in the observed reduction in delivered dose.

The use of heparin or regional citrate anticoagulation may prevent interruptions due to filter clotting. When using regional citrate anticoagulation (anticoagulant citrate dextrose solution A), a relationship between BFR and citrate rate should be maintained (typically $1: 1.5-2$ ) to achieve a blood citrate concentration of $4-6 \mathrm{mmol} / \mathrm{L}$ in the extracorporeal circuit (circuit ionized calcium of $<0.35 \mathrm{mmol} / \mathrm{L}$ ) [35]. When CRRT is delivered without regional citrate anticoagulation, BFR is typically maintained at $\geq 200 \mathrm{~mL} / \mathrm{min}$ to theoretically increase filter life by attenuating FF. However, in a randomized controlled trial comparing CRRT without regional citrate anticoagulation with BFR of 150 versus $250 \mathrm{~mL} / \mathrm{min}$, there was no difference in circuit clotting or median circuit lifespan of first CRRT circuit in both groups ( 9.1 vs. $10 \mathrm{~h}, p=0.37$, respectively) [36].

Interruptions during CRRT can unintendedly occur due to malfunction alarms, filter clogging/clotting, catheter dysfunction, or bag/tubing changes or intendedly occur due to interruptions for surgical or radiological procedures that require mobilizing the patient outside the room. However, there are no proven strategies to compensate for the decrease in delivered CRRT dose due to circuit downtime. Therefore, one should account for 10$15 \%$ of circuit downtime on average when prescribing CRRT dose. This means that the total prescribed effluent 
Table 2. Randomized Clinical Trials assessing dose of CRRT in critically ill patients with AKI

\begin{tabular}{|c|c|c|c|c|}
\hline Study & Population & Dose comparison & Primary outcome & Comments \\
\hline $\begin{array}{l}\text { Ronco et al. [10] } \\
\text { SS-RCT }\end{array}$ & $\begin{array}{l}N=425 \\
\text { Predominantly } \\
\text { postsurgical AKI }\end{array}$ & $\begin{array}{l}\text { Post-dilution CVVHF } \\
20 \mathrm{~mL} / \mathrm{kg} / \mathrm{h} \text { versus } \\
35 \mathrm{~mL} / \mathrm{kg} / \mathrm{h} \text { versus } \\
45 \mathrm{~mL} / \mathrm{kg} / \mathrm{h}\end{array}$ & $\begin{array}{l}\text { 15-day survival } \\
59 \% \text { versus } \\
43 \% \text { versus } \\
42 \% \\
p<0.002 \text { for comparison of } \\
20 \text { versus } 35 \text { and } p=\text { ns for } \\
\text { comparison of } 35 \text { versus } 45\end{array}$ & $\begin{array}{l}90-95 \% \text { recovery of kidney function } \\
\text { in survivors }\end{array}$ \\
\hline $\begin{array}{l}\text { Bouman et al. [39] } \\
\text { 2C-RCT }\end{array}$ & $\begin{array}{l}N=106 \\
\text { Postsurgical AKI }\end{array}$ & $\begin{array}{l}\text { CVVH } \\
\text { 72-96 L/day early versus } \\
24-36 \mathrm{~L} / \text { day early versus } \\
24-36 \mathrm{~L} \text { /day late }\end{array}$ & $\begin{array}{l}\text { 28-day survival } \\
74 \% \text { versus } \\
69 \% \text { versus } \\
75 \% \\
p=\text { ns for comparison of } \\
24-36 \text { versus } 72-96 \text { (early) }\end{array}$ & $\begin{array}{l}\text { All hospital survivors had kidney } \\
\text { recovery at discharge, except for } 1 \\
\text { patient }\end{array}$ \\
\hline $\begin{array}{l}\text { ATN [43] } \\
\text { MC-RCT }\end{array}$ & $\begin{array}{l}N=1,124 \\
\text { Multifactorial AKI }\end{array}$ & $\begin{array}{l}\text { Predilution CVVHDF } \\
35 \mathrm{~mL} / \mathrm{kg} / \mathrm{h} \text { or } 6 / \text { week SLEDD or } \\
\text { 6/week IHD versus } \\
\text { Predilution CVVHDF } \\
20 \mathrm{~mL} / \mathrm{kg} / \mathrm{h} \text { or } 3 / \text { week SLEDD or } \\
\text { 3/week IHD }\end{array}$ & $\begin{array}{l}\text { 60-day mortality } \\
46 \% \text { versus } \\
48 \%(p=n s)\end{array}$ & $\begin{array}{l}\text { At day } 28 \text {, no differences in complete } \\
\text { or partial recovery of kidney function }\end{array}$ \\
\hline $\begin{array}{l}\text { RENAL [44] } \\
\text { MC-RCT }\end{array}$ & $\begin{array}{l}N=1,508 \\
\text { Critically ill patients } \\
\text { with AKI }\end{array}$ & $\begin{array}{l}\text { Postdilution CVVHDF } \\
40 \mathrm{~mL} / \mathrm{kg} / \mathrm{h} \text { versus } \\
25 \mathrm{~m} / \mathrm{kg} / \mathrm{h}\end{array}$ & $\begin{array}{l}\text { 90-day mortality } \\
55 \% \text { versus } \\
55 \%(p=\mathrm{ns})\end{array}$ & $\begin{array}{l}\text { No difference in recovery of kidney } \\
\text { function or dependence on RRT }\end{array}$ \\
\hline
\end{tabular}

RCT, randomized controlled trial; 2C-RCT, two-center RCT; AKI, acute kidney injury; CVVH, continuous venovenous hemofiltration; CVVHD, continuous venovenous hemodialysis; CVVHDF, continuous venovenous hemodiafiltration; HD, hemodialysis; HF, hemofiltration; ICU, intensive care unit; IHD, intermittent hemodialysis; MC-RCT, multicenter RCT; ns, not significant; RRT, renal replacement therapy; SLEDD, sustained low-efficiency daily dialysis; ATN, Acute Renal Failure Trial Network; RENAL, Randomized Evaluation of Normal versus Augmented Level; SS-RCT, single-center RCT.

dose should be $25-30 \mathrm{~mL} / \mathrm{kg} / \mathrm{h}(10-15 \%$ above the recommended delivered effluent dose of $20-25 \mathrm{~mL} / \mathrm{kg} / \mathrm{h}$ ) [37]. The concepts of average delivered CRRT dose, the dose delivered over the effective treatment time, and quality indicators related to delivered CRRT dose are represented in Figures 1 and $2[11,16]$.

\section{Interventional Studies Examining CRRT Dose in Heterogeneous ICU Populations}

There have been several interventional studies examining the relationship of CRRT dose with overall survival and kidney recovery among critically ill patients on CRRT as shown in Table 2 [38]. Ronco et al. [10] tested different doses of CVVH and did not find a difference in mortality when effluent doses of 45 versus $35 \mathrm{~mL} / \mathrm{kg} / \mathrm{h}$ were compared. Similarly, there was no difference in mortality or kidney recovery when higher doses of CVVH or CVVHDF $(35-48 \mathrm{~mL} / \mathrm{kg} / \mathrm{h})$ were compared to a standard dose of $20 \mathrm{~mL} / \mathrm{kg} / \mathrm{h}[39,40]$. Only 1 study reported improved survival at 28 and 90 days with higher doses of CVVH ( 42 vs. $25 \mathrm{~mL} / \mathrm{kg} / \mathrm{h}$ ) [5]. Overall, the aforementioned studies were relatively small and/or single-center. In this context, 2 large multicenter clinical trials, the Acute Renal Failure Trial Network (ATN) and the Randomized Evaluation of Normal versus Augmented Level (RENAL), were conducted and concluded that there were no differences in mortality or kidney recovery outcomes when high-intensity $(35-40 \mathrm{~mL} / \mathrm{kg} / \mathrm{h})$ versus standard- 
intensity (20-25 mL/kg/h) CRRT doses were compared [41-44].

The conclusions of these 2 large interventional studies were further supported by a 2016 Cochrane systematic review stating that higher dose of CRRT does not impact favorably on mortality or recovery of kidney function in critically ill patients with AKI and increases the risk of hypophosphatemia [45]. Two additional metanalyse concluded that higher intensity RRT does not impact mortality outcome $[46,47]$.

In a different study, Combes et al. [48] randomized patients with post-cardiac surgery shock and severe AKI to delayed CVVHDF (standard indications) versus early high-volume hemofiltration (HVHF, $80 \mathrm{~mL} / \mathrm{kg} / \mathrm{h}$ ) for $48 \mathrm{~h}$ followed by standard-dose CVVHDF ( $<35 \mathrm{~mL} / \mathrm{kg} / \mathrm{h})$ until resolution of shock and kidney recovery and did not observe differences in mortality rates. Similar studies have further tested the hypothesis that HVHF may improve hemodynamics and mortality in critically ill septic patients with AKI by removal of pro-inflammatory cytokines; however, no difference was found in mortality outcomes [49-52]. A recent metanalysis by Clark et al. [53] included 4 randomized clinical trials examining potential benefits of HVHF in critically ill septic patients with AKI and concluded that current evidence is insufficient to support the routine use of HVHF in this specific subpopulation. More interventional studies are needed to further assess the non-selective convective clearance of cytokines in specific subpopulations such as critically ill septic patients.

\section{How to Operationalize the Systematic Monitoring of CRRT Dose?}

The approach to the systematic evaluation of CRRT dose as a quality indicator of CRRT delivery should be supported by evolving implementation science and logistics specific to each institution. Some previously reported interventions for improving the average delivered CRRT dose include the development of electronic flow sheets to continuously report delivered CRRT dose according to predetermined time intervals, the standardization of CRRT prescription and documentation templates, and the enhancement of education to nurses, clinicians, and the overall multidisciplinary CRRT team $[13,54]$.

A recent study by Griffin et al. [13] demonstrated an improvement in mean delivered CRRT dose in patients receiving $\mathrm{CVVH}$ by implementing a quality assurance program. The intervention consisted of (1) incorporating an average 24-h CRRT delivered dose into the electronic flow sheet; (2) adding CRRT delivered dose to the procedure note; (3) modifying the CRRT order set to display dose calculations; and (4) educational sessions. Before the intervention, only 279 of 837 (33\%) treatments achieved an average daily delivered effluent dose of $20-25 \mathrm{~mL} /$ $\mathrm{kg} / \mathrm{h}$, but following the intervention, 631 of 952 (66\%) treatments achieved an average daily delivered effluent dose of $20-25 \mathrm{~mL} / \mathrm{kg} / \mathrm{h}$, as recommended by the KDIGO guidelines [13]. One should note that local needs and expertise, available logistics, and the specific timeline of goals and implementation strategies should be evaluated before prioritizing quality improvement initiatives at each institution [54].

\section{Summary Statement}

There is no evidence to support that the average highintensity CRRT dose (prescribed effluent fluid rate $>35$ $40 \mathrm{~mL} / \mathrm{kg} / \mathrm{h}$ ) favorably impacts mortality or kidney recovery when compared to the standard CRRT dose (prescribed effluent fluid rate $\sim 25-30 \mathrm{~mL} / \mathrm{kg} / \mathrm{h}$ ). However, one may consider - albeit transiently - adjustments in CRRT dose to individualize therapy according to specific solute or volume control goals in acutely ill patients with AKI in need of CRRT. Consideration should be given to estimates of circuit downtime, which attenuates the effective delivery of the prescribed dose of CRRT. Finally, delivered CRRT dose constitutes a trackable quality indicator that should be systematically monitored by effective quality assurance systems during the provision of CRRT in the ICU. The impact of adhering to evidence-based practices of delivered CRRT dose on clinical and patientcentered outcomes requires further investigation.

\section{Acknowledgments}

Dr. Neyra is currently supported by grants from NIDDK (R56 DK126930 and P30 DK079337) and NHLBI (R01 HL148448-01 and R21 HL145424-01A1). The authors would like to thank Dr. Matthew Sparks for his thoughtful review of this manuscript.

\section{Conflict of Interest Statement}

Dr. Neyra has consulted for Baxter Healthcare and Renibus Therapeutics.
Vásquez Jiménez/Anumudu/Neyra 


\section{References}

1 Tolwani A. Continuous renal-replacement therapy for acute kidney injury. N Engl J Med. 2012;367(26):2505-14.

2 RENAL Replacement Therapy Study Investigators; Bellomo R, Cass A, Cole L, Finfer S, Gallagher $M$, et al. Intensity of continuous renal-replacement therapy in critically ill patients. N Engl J Med. 2009;361(17):1627-38.

3 Ostermann M, Chang R. Correlation between the AKI classification and outcome. Crit Care. 2008;12(6):R144.

4 Liu KD, Himmelfarb J, Paganini E, Ikizler TA, Soroko SH, Mehta RL, et al. Timing of initiation of dialysis in critically ill patients with acute kidney injury. Clin J Am Soc Nephrol. 2006;1(5):915-9.

5 Saudan P, Niederberger M, De Seigneux S, Romand J, Pugin J, Perneger T, et al. Adding a dialysis dose to continuous hemofiltration increases survival in patients with acute renal failure. Kidney Int. 2006;70(7):1312-7.

6 Uchino S, Kellum JA, Bellomo R, Doig GS, Morimatsu H, Morgera S, et al. Acute renal failure in critically ill patients: a multinational, multicenter study. JAMA. 2005;294(7): 813-8.

7 Tandukar S, Palevsky PM. Continuous renal replacement therapy: who, when, why, and how. Chest. 2019;155(3):626-38.

8 Hoste EA, Bagshaw SM, Bellomo R, Cely CM, Colman R, Cruz DN, et al. Epidemiology of acute kidney injury in critically ill patients: the multinational AKI-EPI study. Intensive Care Med. 2015;41(8):1411-23.

9 Claure-Del Granado R, Macedo E, Chertow GM, Soroko S, Himmelfarb J, Ikizler TA, et al. Toward the optimal dose metric in continuous renal replacement therapy. Int J Artif Organs. 2012;35(6):413-24.

10 Ronco C, Bellomo R, Homel P, Brendolan A, Dan M, Piccinni P, et al. Effects of different doses in continuous veno-venous hemofiltration on outcomes of acute renal failure: a prospective randomized trial. Lancet. 2000;356 26-30.

11 Neri M, Villa G, Garzotto F, Bagshaw S, Bellomo R, Cerda J, et al. Nomenclature for renal replacement therapy in acute kidney injury: basic principles. Crit Care. 2016;20(1):318.

12 Prowle JR, Bellomo R. Continuous renal replacement therapy: recent advances and future research. Nat Rev Nephrol. 2010;6(9): 521-9.

13 Griffin BR, Thomson A, Yoder M, Francis I, Ambruso S, Bregman A, et al. Continuous renal replacement therapy dosing in critically il patients: a quality improvement initiative. Am J Kidney Dis. 2019;74(6):727-35.

14 Rewa O, Mottes T, Bagshaw SM. Quality measures for acute kidney injury and continuous renal replacement therapy. Curr Opin Crit Care. 2015;21(6):490-9.
15 Bagshaw SM, Chakravarthi MR, Ricci Z, Tolwani A, Neri M, De Rosa S, et al. Precision continuous renal replacement therapy and solute control. Blood Purif. 2016;42(3):23847.

16 Rewa OG, Tolwani A, Mottes T, Juncos LA, Ronco C, Kashani K, et al. Quality of care and safety measures of acute renal replacement therapy: workgroup statements from the 22nd acute disease quality initiative (ADQI) consensus conference. J Crit Care. 2019;54: 52-7.

17 Rewa OG, Villeneuve PM, Lachance P, Eurich DT, Stelfox HT, Gibney RTN, et al. Quality indicators of continuous renal replacement therapy (CRRT) care in critically ill patients: a systematic review. Intensive Care Med. 2017;43(6):750-63.

18 Rewa OG, Eurich DT, Noel Gibney RT, Bagshaw SM. A modified delphi process to identify, rank and prioritize quality indicators for continuous renal replacement therapy (CRRT) care in critically ill patients. J Crit Care. 2018;47:145-52.

19 Lemarie P, Husser-Vidal S, Gergaud S, Verger $\mathrm{X}$, Rineau E, Berton J, et al. High-fidelity simulation nurse training reduces unplanned interruption of continuous renal replacement therapy sessions in critically ill patients: the simHeR randomized controlled trial. Anesth Analg. 2019;129(1):121-8.

20 Mottes TA, Goldstein SL, Basu RK. Process based quality improvement using a continuous renal replacement therapy dashboard. BMC Nephrol. 2019;20(1):17.

21 Cerdá J, Ronco C. The clinical application of crrt-current status: modalities of continuous renal replacement therapy: technical and clinical considerations. Semin Dial. 2009;22:11422.

22 Brunet S, Leblanc M, Geadah D, Parent D, Courteau S, Cardinal J. Diffusive and convective solute clearances during continuous renal replacement therapy at various dialysate and ultrafiltration flow rates. Am J Kidney Dis. 1999;34(3):486-92.

23 Hatamizadeh P, Tolwani A, Palevsky P. Revisiting filtration fraction as an index of the risk of hemofilter clotting in continuous venovenous hemofiltration. Clin J Am Soc Nephrol. 2020;15(11):1660-2.

24 Troyanov S, Cardinal J, Geadah D, Parent D, Courteau S, Caron S, et al. Solute clearances during continuous venovenous haemofiltration at various ultrafiltration flow rates using multiflow-100 and HF1000 filters. Nephrol Dial Transplant. 2003;18(5):961-6.

25 Clark WR, Turk JE, Kraus MA, Gao D. Dose determinants in continuous renal replacement therapy. Artif Organs. 2003;27(9):81520.

26 KDIGO clinical practice guideline for acute kidney injury: dose of renal replacement therapy in AKI. Kidney Int. 2012;2:113-5.
27 Palevsky PM, Liu KD, Brophy PD, Chawla LS Parikh CR, Thakar CV, et al. KDOQI US commentary on the 2012 KDIGO clinical practice guideline for acute kidney injury. Am J Kidney Dis. 2013;61(5):649-72.

28 Macedo E, Claure-Del Granado R, Mehta RL. Effluent volume and dialysis dose in CRRT: time for reappraisal. Nat Rev Nephrol. 2011; 8(1):57-60.

29 Claure-Del Granado R, Macedo E, Chertow GM, Soroko S, Himmelfarb J, Ikizler TA, et al. Effluent volume in continuous renal replacement therapy overestimates the delivered dose of dialysis. Clin J Am Soc Nephrol. 2011; 6(3):467-75.

30 Marshall MR. Current status of dosing and quantification of acute renal replacement therapy. Part 1: mechanisms and consequences of therapy under-delivery. Nephrology. 2006;11(3):171-80.

31 Feldhoff P, Turnham T, Klein E. Effect of plasma proteins on the sieving spectra of hemofilters. Artif Organs. 1984;8(2):186-92.

32 Venkataraman R, Kellum JA, Palevsky P. Dosing patterns for continuous renal replacement therapy at a large academic medical center in the united states. J Crit Care. 2002;17(4): 246-50.

33 Vesconi S, Cruz DN, Fumagalli R, KindgenMilles D, Monti G, Marinho A, et al. Delivered dose of renal replacement therapy and mortality in critically ill patients with acute kidney injury. Crit Care. 2009;13(2):R57.

34 Zhang Z, Ni H, Fan H, Li D, Xu X. Actually delivered dose of continuous renal replacement therapy is underestimated in hemofiltration. ASAIO J. 2013;59(6):622-6.

35 Davenport A, Tolwani A. Citrate anticoagulation for continuous renal replacement therapy (CRRT) in patients with acute kidney injury admitted to the intensive care unit. NDT Plus. 2009;2(6):439-47.

36 Fealy N, Aitken L, du Toit E, Lo S, Baldwin I. Faster blood flow rate does not improve circuit life in continuous renal replacement therapy: a randomized controlled trial. Crit Care Med. 2017 Oct;45(10):e1018-25.

37 Connor MJ Jr, Karakala N. Continuous renal replacement therapy: reviewing current best practice to provide high-quality extracorporeal therapy to critically ill patients. Adv Chronic Kidney Dis. 2017;24(4):213-8.

38 Prowle JR, Schneider A, Bellomo R. Clinical review: optimal dose of continuous renal replacement therapy in acute kidney injury. Crit Care. 2011;15(2):207.

39 Bouman CS, Oudemans-Van Straaten HM, Tijssen JG, Zandstra DF, Kesecioglu J. Effects of early high-volume continuous venovenous hemofiltration on survival and recovery of renal function in intensive care patients with acute renal failure: a prospective, randomized trial. Crit Care Med. 2002;30(10):2205-11.
Dose of Continuous Renal Replacement Therapy in Critically Ill Patients
Nephron 2021;145:91-98 DOI: $10.1159 / 000512846$ 
40 Tolwani AJ, Campbell RC, Stofan BS, Lai KR, Oster RA, Wille KM. Standard versus highdose CVVHDF for ICU-related acute renal failure. J Am Soc Nephrol. 2008;19(6):12338.

41 Macedo E, Mehta RL. Continuous dialysis therapies: core curriculum. Am J Kidney Dis. 2016;68:645-57.

42 Clark WR, Leblanc M, Ricci Z, Ronco C. Quantification and dosing of renal replacement therapy in acute kidney injury: a reappraisal. Blood Purif. 2017;44(2):140-55.

43 VA/NIH Acute Renal Failure Trial Network; Palevsky PM, Zhang JH, O'Connor TZ, Chertow GM, Crowley ST, et al. Intensity of renal support in critically ill patients with acute kidney injury. N Engl J Med. 2008;359(1):7-20.

44 RENAL Replacement Therapy Study Investigators; Bellomo R, Cass A, Cole L, Finfer S, Gallagher $\mathrm{M}$, et al. Intensity of continuous renal-replacement therapy in critically ill patients. N Engl J Med. 2009;361(17):1627-38.

45 Fayad AI, Buamscha DG, Ciapponi A. Intensity of continuous renal replacement therapy for acute kidney injury. Cochrane Database Syst Rev. 2016;10:CD010613.
46 Wang Y, Gallagher M, Li Q, Lo S, Cass A, Finfer $S$, et al. Renal replacement therapy intensity for acute kidney injury and recovery to dialysis independence: a systematic review and individual patient data meta-analysis. Nephrol Dial Transplant. 2018;33(6):101724.

47 Jun M, Heerspink HJ, Ninomiya T, Gallagher M, Bellomo R, Myburgh J, et al. Intensities of renal replacement therapy in acute kidney injury: a systematic review and metaanalysis. Clin J Am Soc Nephrol. 2010;5(6): 956-63.

48 Combes A, Bréchot N, Amour J, Cozic N, Lebreton G, Guidon C, et al. Early high-volume hemofiltration versus standard care for postcardiac surgery shock. The HEROICS study. Am J Respir Crit Care Med. 2015;192(10): 1179-90.

49 Joannes-Boyau O, Honore PM, Perez P, Bagshaw SM, Grand H, Canivet JL, et al. Highvolume versus standard volume haemofiltration for septic shock patients with acute kidney injury (IVOIRE study): a multicentre randomized controlled trial. Intensive Care Med. 2013;39:1535-46.
50 Boussekey N, Chiche A, Faure K, Devos P, Guery B, d'Escrivan T, et al. A pilot randomized study comparing high and low volume hemofiltration on vasopressor use in septic shock. Intensive Care Med. 2008;34(9):1646-53.

51 Zhang P, Yang Y, Lv R, Zhang Y, Xie W, Chen $J$. Effect of the intensity of continuous renal replacement therapy in patients with sepsis and acute kidney injury: a single-center randomized clinical trial. Nephrol Dial Transplant. 2012;27(3):967-73.

52 Park JT, Lee H, Kee YK, Park S, Oh HJ, Han $\mathrm{SH}$, et al. High-dose versus conventional-dose continuous venovenous hemodiafiltration and patient and kidney survival and cytokine removal in sepsis-associated acute kidney injury: a randomized controlled trial. Am J Kidney Dis. 2016;68(4):599-608.

53 Clark E, Molnar AO, Joannes-Boyau O, Honoré PM, Sikora L, Bagshaw SM. High-volume hemofiltration for septic acute kidney injury: a systematic review and meta-analysis. Crit Care. 2014;18(1):R7.

54 Neyra JA, Tolwani AJ. A quality improvement initiative targeting CRRT delivered dose: the what, the how, and the why. Am J Kidney Dis. 2019;74(6):721-3. 